Research Article

\title{
Effect of Larval Nutritional Regimes on Morphometry and Vectorial Capacity of Aedes aegypti for Dengue Transmission
}

\author{
Nayana Gunathilaka $\left(\mathbb{D},{ }^{1}\right.$ Hasini Upulika, ${ }^{2}$ Lahiru Udayanga $\left(\mathbb{D},{ }^{3}\right.$ \\ and Deepika Amarasinghe $\mathbb{1}^{2}$ \\ ${ }^{1}$ Department of Parasitology, Faculty of Medicine, University of Kelaniya, Ragama, Sri Lanka \\ ${ }^{2}$ Department of Zoology and Environment Management, Faculty of Science, University of Kelaniya, Dalugama, Sri Lanka \\ ${ }^{3}$ Department of Bio-systems Engineering, Faculty of Agriculture and Plantation Management, Wayamba University of Sri Lanka, \\ Makandura, Sri Lanka
}

Correspondence should be addressed to Nayana Gunathilaka; n.gunathilaka@kln.ac.lk

Received 17 May 2019; Revised 25 July 2019; Accepted 16 September 2019; Published 9 October 2019

Academic Editor: Frederick D. Quinn

Copyright (c) 2019 Nayana Gunathilaka et al. This is an open access article distributed under the Creative Commons Attribution License, which permits unrestricted use, distribution, and reproduction in any medium, provided the original work is properly cited.

\begin{abstract}
Background. Nutritional level in larval diet of mosquito vectors influence on life history traits and vectorial capacity (VC). Therefore, the present study was carried out to assess the effect of larval diet concentration on vector bionomic and VC of Aedes aegypti in Sri Lanka. Method. Three batches of 400 Ae. aegypti larvae (first instar) were reared under different concentrations of larval diet (6\%,8\%, and 10\%; Volume/Volume), which was prepared by mixing $12.5 \mathrm{~g}$ of tuna meal, $9.0 \mathrm{~g}$ of bovine liver powder, and $3.5 \mathrm{~g}$ of Brewer's yeast, in $100 \mathrm{ml}$ of distilled water. The effect of larval diet concentration on different morphometric and functional parameters of larvae (length and width of head, abdomen, survival rate, and pupation success), pupae (length and width of cephalothorax, survival rate, and adult emersion), adult (length and width of thorax, abdomen, survival rate, longevity, biting frequency and fecundity of adults) were examined. In addition, VC of Ae. aegypti was evaluated. The General Linear Model (GLM) was used for the statistical analysis. Results. Larval head length, head width, thoracic width, abdominal length, abdominal width, total length, and survival rate significantly increased with higher doses of larval diet $(P<0.05)$. In case of pupae, length, and width of cephalothorax, survival rate and adult emergence rate denoted an increasing trend with the elevated larval diets. However, the variations of survival rate and adult emergence rate were statistically significant $(P<0.05)$. In adults, all morphometric parameters (thoracic length, abdominal length, abdominal width, and wing length) significantly increased with elevating larval diets levels (except for thoracic width) along with the biting frequency, fecundity, and survival rate $(P<0.05)$ of adult females. The VC also denoted significant variations $\left(F_{4,14}=24.048 ; P<0.05\right)$ with the larval diet concentration, whereby the highest VC of 196.37 was observed at $10 \%$ treatment. Conclusion. Larval food availability has a significant influence on the adult fitness and thus may affect the incidence of dengue due to variations in the $\mathrm{VC}$ of Ae. aegypti. Hence, this investigation highlights the requirement in accounting the environmental variation at the larval stages in order to understand transmission dynamics and control of dengue in Sri Lanka.
\end{abstract}

\section{Introduction}

Mosquitoes (Diptera; Culicidae) are one of the major threats for millions of people as they act as vectors of large number of infections of pathogens and parasites, namely, malaria, filariasis, and viral infections such as dengue, encephalitis, and yellow fever [1]. Aedes aegypti, an invasive species that has been identified in six continents, is frequently dispersed by human activities and represents a serious threat to public health, due to its ability to transmit numerous vector-borne diseases such as urban yellow fever (African and American tropics), dengue, zika, and chikungunya throughout most of the tropical world [2]. It has now become the most widespread mosquito species globally [3-6].

Dengue is a rapidly emerging arthropod-borne virus which is transmitted to humans mainly by Ae. aegypti and 
Ae. albopictus [7]. In Sri Lanka, dengue has been notified as one of the major public health concerns in recent years recording the highest ever cases of dengue in 2017 denoting 186,00 cases from the country and 51,584 cases in 2018 [8].

As there is no effective vaccine or antiviral treatment available up to now for dengue, current dengue prevention efforts are mainly driven on vector control strategies which integrate the use of insecticides with natural enemies, elimination of breeding sites, and physical approaches $[9,10]$. However, reduction of dengue incidence through vector control still remains as a challenge in Sri Lanka, despite of continuous control efforts, due to limited knowledge and understanding on the ecological factors that regulate dengue transmission and their relative importance in disease prevention and management [10].

Ae. aegypti larvae utilize a large variety of habitats enriched with different food types including microorganisms, detritus, biofilm, and other organic matter such as dead invertebrates, plant materials that has been degraded by fungi or bacteria [11]. Further, Ae. aegypti larvae use a variety of feeding methods such as collecting-gathering, scraping, shredding, and predation [11]. Ae. aegypti larvae require a diet comprising glucose, salts, lipids, RNA, 17 amino acids, glutathione, and 12 vitamins. Larvae of Ae. aegypti can survive with a chemically defined diet consisting of glucose, salt mixture, lipids, RNA, 17 amino acids, glutathione, and 12 vitamins. It has been investigated that valine, L-leucine, Lisoleucine, L-phenylalanine, L-histidine, L-arginine, L-tryptophane, L-threonine, L-methionine, and L-lysine essential are for larval growth. In addition, L-cystine is essential for pupation and L-proline, L-hydroxyproline, and L-serine are required for normal growth and development. Therefore, the larval diet should be enriched with amino acids. The absence of vitamin $\mathrm{B}_{12}$ delays pupation and $p$-aminobenzoic acid interruptions ecdysis [12].

Many studies have highlighted that the residing environment of larval stages of mosquitoes strongly determines the adult characteristics such as individual size, teneral reserves, biting behavior, fecundity, longevity, and vector competence, which affect the overall vectorial capacity [13-16]. Any change in the environment that affects the related aspect of vector biology may result in a variation in risk of disease transmission via influencing the vectorial capacity [17]. At present, many investigations that evaluate the effect of environment on mosquito biology and aspects of Vectorial Capacity (VC) have directly focused on adult mosquitoes, with limited attention on larval stages.

There have been epidemiological models and mathematical based approaches to determine the $\mathrm{VC}$ of disease vectors. However, such approaches have not been evaluated for mosquito vectors in Sri Lanka under field or laboratory conditions. Therefore, objective of the present study was to explore the VC of Ae. aegypti, which is the main vector for dengue transmission in Sri Lanka under laboratory settings at different larval rearing conditions using mathematical based interpretation.

\section{Method}

\subsection{Establishment of an Ae. aegypti Mosquito Colony for the Experiment}

2.1.1. Rearing of Immature Stages. An Ae. aegypti colony, maintained at the Department of Parasitology, Faculty of Medicine, University of Kelaniya, Sri Lanka, that has been established from eggs collected from an ovitrap surveillance conducted within the Ragama Medical Officer of Health area was used to collect the eggs for the current study. Laboratory reared colony after 5 generations, which was adapted to laboratory conditions were taken for the study. Eggs sheets were soaked in deoxygenated distilled water and kept for 1hour duration at room temperature $\left(25^{\circ} \mathrm{C}-28^{\circ} \mathrm{C}\right)$. The first instar larvae were collected after 1 hour using a pasture pipette. Larvae were transferred into larval rearing trays $(25 \times 25 \times 7 \mathrm{~cm})$ and reared with a daily dose of larval diet comprising $12.5 \mathrm{~g}$ of tuna meal, $9.0 \mathrm{~g}$ of bovine liver powder, and $3.5 \mathrm{~g}$ of brewer's yeast dissolved in $100 \mathrm{ml}$ of distilled water. Pupae were sorted daily for larval trays and transferred into pupal rearing cups ( $50 \mathrm{ml}$ capacity) using a pasture pipette $[18,19]$.

2.1.2. Rearing of Adult Ae. aegypti. Pupal rearing cups were kept inside adult mosquito rearing cages $(30 \times 30 \times 30 \mathrm{~cm})$ until the emergence of adults. Newly emerged adult mosquitoes were provided with $10 \%$ sugar solution and vitamin complex ( $1 \mathrm{ml})$. After 24 hours of initial sugar feeding, the adult female mosquitoes were allowed to feed on human blood using an artificial metal plate membrane feeding system [19]. Human blood was collected from a healthy volunteer $(<18$ years) under sterile conditions by a trained technical officer under supervision of a Medical Officer at the Faculty of Medicine, University of Kelaniya, Sri Lanka.

The written consent from the donor was obtained prior collection of blood. Blood fed females were maintained under a 12:12 (light: dark) cycle. The adult rearing cages were covered with wet towels to maintain the humidity at $75 \pm 5 \%$ and the temperature was maintained at $27 \pm 2^{\circ} \mathrm{C}$. Sugar and vitamin syrup were kept available for adult mosquitoes. Oviposition cups (diameter $9.5 \mathrm{~cm}$, height $5 \mathrm{~cm}$ ) lined with a strip of white colored filter paper was kept inside the adult cages three days after the initial blood meal. Eggs deposited on the lined filter paper were used to maintain the mosquito colony throughout the experimental trials.

\subsection{Influence of Larval Food Quantity on Survival and Development}

2.2.1. Larval Feeding Experiment. Three batches of 400 first instar larvae (L1) of Ae. aegypti were counted and transferred in to three separated larval rearing trays $(25 \times 25 \times 7 \mathrm{~cm})$ containing $500 \mathrm{ml}$ of deionized water. Each tray was treated with different volumes of larval diet $(100 \% \mathrm{vol} / \mathrm{vol})$ as shown in the Table 1.

The larval diet mentioned in Table 1 was provided twice a day (morning and evening) until pupation. Excessive food, 
TABLE 1: Composition of larval diet in different concentration and feeding arrangement.

\begin{tabular}{lccc}
\hline Tray no. & Larval diet volume introduced $(\mathrm{ml})$ & Diet concentration $(\mathrm{vol} / \mathrm{vol})(\%)$ & No. of larvae at one trial $(n)$ \\
\hline 1 & 0.25 & 10 & 400 \\
2 & 0.20 & 8 & 400 \\
3 & 0.15 & 6 & 400 \\
\hline
\end{tabular}

fecal matter, and debris in the larval trays were removed daily using pasture pipettes, in order to maintain satisfactory water quality levels for larval development. All larval trays were examined daily at 09:00 and 15:00 h, and pupae that had formed were manually collected. The pupae were counted and placed in transparent plastic vials $(50 \mathrm{ml} \mathrm{ca-}$ pacity) filled with $25 \mathrm{ml}$ of deionized water and were covered with a sponge plug. Adult emergence was also recorded daily, and sex was determined. The experimental setup was repeated five times.

2.3. Morphometric Characterization of Larvae Reared under Different Food Concentrations. Randomly selected five larvae were preserved daily from each diet treatment. Morphometric parameters, namely, head length, head width, thoracic length, thoracic width, abdominal length, abdominal width, and total length of larvae were measured using a stereo microscope (BOECO BST-606, Germany) fixed with a microscopy digital USB camera (Optika 4083. B6) and OPTIKA version 2.12 image processing software.

2.4. Pupation Success and Size Variation of Pupae. Number of emerged pupae and mortality were recorded daily. The pupation success (percentage of larvae that emerged as pupae) was calculated at each dietary concentration [20]. Five pupae from each diet treatment were randomly selected, and selected morphometric characteristics (length and width of the cephalothorax) were measured using the above mentioned stereo microscope.

2.5. Adult Emergence Rate, Oviposition Rate, and Adult Longevity. Emerged adult mosquitoes from each diet treatment were collected and counted. The adult emergence rate was calculated as the percentage of adult mosquitoes emerged from the total number of pupae under each treatment. The sex of the mosquitoes was determined and recorded while transferring to new separated cages provided with $10 \%$ sugar and vitamin B syrup. Females were allowed to feed on human blood using an artificial membrane feeding system 24 hours after sugar feeding [19]. Egg laying cups for females were placed inside cages in order to facilitate the oviposition. The number of eggs in the filter paper were counted every day and replaced with new lining until the colony was over. The durations of adult survival were counted as the longevity of adults [20].

2.6. Size Discrimination of Adult Mosquitoes. Five adult males and females that emerged from each diet treatment were collected randomly into separate collection tubes using mouth aspirators and sacrificed with a cold shock. Wings were separated with a dissecting microscope. The standardized wing length was measured from the distal end of alula to the end of radius vein, excluding fringe scale [18], and the width of the wing was measured at the greatest breadth excluding fringing scales. In addition, measurements were made for thorax width from dorsum to coxae and from the base of neck to base of the abdomen. Abdomen width was measured at the widest point, and the length of the abdomen was measured from base to the tip.

All measurements were taken by using a stereo microscope (BOECO BST-606, Germany) fixed with a microscopy digital USB camera (Optika 4083. B6) and OPTIKA version 2.12 image processing software. The digital images of wing, thorax, and abdomen were made by digital camera mounted stereo microscope with the same magnification $(8 \mathrm{x})$.

2.7. Survival Rates of Larvae, Pupae, and Adults at Different Food Concentrations. The number of surviving larvae, pupae, and adult mosquitoes were observed and recorded twice a day, separately. The survival rate of Ae. aegypti was calculated as the proportion of larvae, pupae, or adults that survived the relevant period in the life cycle over the total number of individuals that were present in the considering life stage at the beginning [18].

2.8. Effect of Larval Food Quantity on Biting Frequency. A total of 20 newly emerged adult mosquitoes from each diet treatment was transferred into a new cage with $1: 1$ sex ratio. A blood meal of human origin was provided artificially for 10 -minute duration in the arms of a human host (a healthy volunteer). The proportion of females that ingested or attempted to ingest blood was observed by three well-trained technical staff members. The biting frequency was estimated as the percentage of females that ingested or attempted to ingest blood over the total number of female mosquitoes $[21,22]$. The experiment was repeated for 5 times.

2.9. Determination of the Vectorial Capacity of Ae. aegypti. Vectorial capacity (VC) of Ae. aegypti treated with different diet concentrations was calculated according to the below mathematical approximation [21]:

$$
\mathrm{VC}=\frac{\mathbf{m a}^{2} \mathbf{p}^{\mathbf{n}}}{-\log e P},
$$

where $\mathbf{m}=$ vector density, $\mathbf{a}=$ average biting frequency, $\mathbf{p}=$ survivorship, and $\mathbf{n}=$ extrinsic incubation period [21]. The vector density was considered as 100 females since 200 Ae. aegypti mosquitoes (with 1:1 male: female ratio) were maintained in a single case for under different treatments. The daily survival rate $P$ was calculated using a mathematical 
formula $\sqrt[d]{P}$, where $d$ is the duration of study (28 days) and $P$ is proportion of females survive by the end of that period [23]. The mean extrinsic incubation period for dengue virus in Ae. aegypti was considered as 6.5 days at $30^{\circ} \mathrm{C}$ (best fitting value for Sri Lankan conditions) as recommended by Chan and Johansson [24].

2.10. Data Processing and Statistical Analysis. All the data were entered into Microsoft Excel Work Sheet and were analyzed using IBM SPSS Statistics (version 23 copyright IBM Corporation). The effect of larval diet concentration on mortality rate, survival rate of larvae, survival rate of pupae, survival rate of adult, pupation success, oviposition rate, longevity of adults, size discrimination of larvae, size discrimination pupae, and size discrimination of adults was analyzed using General Linear Model (GLM), followed by means separation by Tukey's HSD (honest significant difference) at 5\% level of significance. The effect of larval diet concentration on the vectorial capacity and biting frequency was also analyzed using GLM.

\section{Results}

\subsection{Larval Stage}

3.1.1. Effect of Larval Diet on Larval Growth and Survival. Larval food treatment significantly affected the larval growth and survival to pupation. Head length $\left(F_{4,14}=29.599\right.$; $P<0.001)$, head width $\left(F_{4,14}=20.797 ; P<0.001\right)$, thoracic width $\quad\left(F_{4,14}=55.924 ; \quad P<0.001\right), \quad$ abdominal length $\left(F_{4,14}=10.381 ; P<0.001\right)$, abdominal width $\left(F_{4,14}=7.239\right.$; $P=0.001)$, and total length $\left(F_{4,14}=20.797 ; P<0.001\right)$ of the $4^{\text {th }}$ instar Ae. aegypti larvae denoted significant variations with different larval diet concentrate as indicated by the General Liner Model (GLM) at 5\% degree of significance (Table 2).

Larvae reared under $10 \%$ larval diet treatment had the highest head length $(0.66 \pm 0.20 \mathrm{~mm})$, head width $(0.64 \pm 0.20 \mathrm{~mm})$, thoracic width $(0.94 \pm 0.0 \mathrm{~mm})$, abdominal length $(3.74 \pm 0.20 \mathrm{~mm})$, abdominal width $(0.48 \pm 0.04 \mathrm{~mm})$, and total length $(4.95 \pm 0.20 \mathrm{~mm})$. Interestingly, even though the variation of thoracic length of $4^{\text {th }}$ instar was not significant $\left(F_{4,14}=2.136 ; P=0.127\right)$, the highest thoracic length of $0.673 \pm 0.50 \mathrm{~mm}$ was observed from the larvae fed with $10 \%$ larval diet concentration. The lowest values for all the morphological features of $4^{\text {th }}$ instar larvae were observed at $6 \%$ larval diet concentration.

Even though survival rates of larvae gradually increased with the ascending larval diet concentrations, whereby the highest survival rate $(99.5 \pm 0.20 \%)$ was observed at $10 \%$ larval diet concentration, the survival rates of larvae also did not vary significantly $\left(F_{4,14}=0.230 ; P=0.104\right)$ as indicated in Figure 1.

\subsection{Pupal Stage}

3.2.1. Effect of Larval Diet Concentration on Pupation Success, Pupal Morphometry and Survival and Adult Emersion Rates. The pupation success was not significantly associated with the larval diet concentration $\left(F_{4,14}=0.027\right.$; $P=0.973)$ and the pupae originated from the larvae treated with $10 \%$ larval diet had the highest pupation success of $97.80 \pm 0.2 \%$ (Figure 1). The highest cephalothoracic length $(1.80 \pm 0.10 \mathrm{~mm})$ and cephalothoracic width $(1.80 \pm 0.10 \mathrm{~mm})$ of pupae were noted from the $10 \%$ larval diet concentration, while 6\% larval diet concentration denoted the lowest. However, the variation of cephalothoracic length $\left(F_{4,14}=0.907 ; P=0.416\right)$ and cephalothoracic width $\left(F_{4}, 14=2.777 ; P=0.08\right)$ with the larval diet level were not significant (Figure 2).

The survival rate of pupae indicated a significant gradual boost with increasing concentration of larval diet, whereby the highest survival rate of pupae $(99.50 \pm 0.02 \%)$ was observed at $10 \%$ larval diet concentration, while the lowest $(89.10 \pm 0.05 \%)$ was indicated at $6 \%$ concentration level (Figure 3), which remained statistically significant according to $\operatorname{GLM}\left(F_{4,14}=24.011 ; P=0.014\right)$.

\subsection{Adult Stage}

3.3.1. Effect of Larval Diet Concentration on Adult Emersion Rate and Adult Morphometry. The highest adult emersion rate of $86.5 \pm 2.8 \%$ was observed from the $10 \%$ larval diet dose, while the $6 \%$ treatment reported the lowest $(69.0 \pm 3.8 \%)$ as denoted in Figure 3. According to GLM, the adult emersion rates $\left(F_{4,14}=54.14 ; P<0.001\right)$ of pupae of $A e$. aegypti treated with different larval diet concentrations varied significantly. Meanwhile, the mosquito larvae that were subjected to low-diet treatment during larval stages were significantly smaller than that were reared under low diet levels. The thoracic length $\left(F_{4,14}=4.662 ; P=0.014\right)$, abdominal length $\left(F_{4,14}=12.452 ; P=0.001\right)$, abdominal width $\left(F_{4,14}=5.890 ; \quad P=0.05\right)$, and wing length $\left(F_{4,14}=7.001 ; P=0.02\right)$ of adult of Ae. aegypti were significantly affected by varying diet concentrations.

Meanwhile, the thoracic width of adults did not show any significant variances $\left(F_{4,14}=2.469 ; P=0.094\right)$ at different diet concentrations (Table 3 ). On the other hand, the effect of gender on all the above morphometric parameters was significant $(P<0.05)$, except for thoracic length $\left(F_{4,14}=47.38 ; P=0.184\right)$. However, the highest thoracic length $(1.52 \pm 0.03 \mathrm{~mm})$, thoracic width $(1.03 \pm 0.02 \mathrm{~mm})$, abdominal length $(2.83 \pm 0.03 \mathrm{~mm})$, abdominal width $(0.75 \pm 0.01 \mathrm{~mm})$, and wing length $(3.36 \pm 0.03 \mathrm{~mm})$ were observed from female mosquitoes of Ae. aegypti developed under the $10 \%$ larval diet concentration (Table 3).

\subsubsection{Impact of Larval Diet on Functional and Behavioral} Characteristics of Adult Ae. aegypti. Rearing under different larval diet doses resulted in significant variations in biting frequency $\left(F_{4,14}=47.50 ; P<0.001\right)$, fecundity $\left(F_{4,14}=18.33\right.$; $P=0.012)$, and survival rate $\left(F_{4,14}=3.61 ; P=0.016\right)$ of adult female mosquitoes of Ae. aegypti. Interstingly, the longevity of adults of $A$ e. aegypti $\left(F_{4,14}=0.591 ; P=0.608\right)$ did not indicate any significant variations with the different larval diet concentrations in accordance with the GLM. Even though longevity was not significantly affected by larval diet, 
TABle 2: Measurements of $4^{\text {th }}$ instar larvae Aedes aegypti fed with different concentration of larval diet.

\begin{tabular}{|c|c|c|c|c|c|c|c|}
\hline $\begin{array}{l}\text { Larval diet } \\
\text { concentration (\%) }\end{array}$ & $\begin{array}{l}\text { Head length } \\
(\mathrm{mm})\end{array}$ & $\begin{array}{l}\text { Head width } \\
(\mathrm{mm})\end{array}$ & $\begin{array}{c}\text { Thoracic length } \\
(\mathrm{mm})\end{array}$ & $\begin{array}{l}\text { Thoracic width } \\
\text { (mm) }\end{array}$ & $\begin{array}{c}\text { Abdominal } \\
\text { length (mm) }\end{array}$ & $\begin{array}{c}\text { Abdominal } \\
\text { width }(\mathrm{mm})\end{array}$ & $\begin{array}{l}\text { Total length } \\
(\mathrm{mm})\end{array}$ \\
\hline 6 & $\begin{array}{l}0.51 \pm 0.20^{\mathrm{a}} \\
(0.31-0.71)\end{array}$ & $\begin{array}{l}0.53 \pm 0.20^{\mathrm{a}} \\
(0.33-0.73)\end{array}$ & $\begin{array}{l}0.56 \pm 0.50^{\mathrm{a}} \\
(1.06-0.06)\end{array}$ & $\begin{array}{l}0.55 \pm 0.04^{\mathrm{a}} \\
(0.51-0.59)\end{array}$ & $\begin{array}{l}2.85 \pm 0.20^{\mathrm{a}} \\
(2.65-3.05)\end{array}$ & $\begin{array}{l}0.31 \pm 0.04^{\mathrm{a}} \\
(0.27-0.35)\end{array}$ & $\begin{array}{l}3.90 \pm 0.20^{\mathrm{a}} \\
(3.70-4.10)\end{array}$ \\
\hline 8 & $\begin{array}{l}0.56 \pm 0.20^{\mathrm{b}} \\
(0.36-0.76)\end{array}$ & $\begin{array}{l}0.54 \pm 0.20^{\mathrm{a}} \\
(0.34-0.74)\end{array}$ & $\begin{array}{l}0.58 \pm 0.50^{\mathrm{a}} \\
(1.08-0.08)\end{array}$ & $\begin{array}{l}0.59 \pm 0.04^{\mathrm{a}} \\
(0.55-0.63)\end{array}$ & $\begin{array}{l}3.33 \pm 0.20^{\mathrm{b}} \\
(3.13-3.53)\end{array}$ & $\begin{array}{c}0.39 \pm 0.04^{\mathrm{a}, \mathrm{b}} \\
(0.35-0.43)\end{array}$ & $\begin{array}{l}4.35 \pm 0.20^{\mathrm{a}} \\
(4.15-4.55)\end{array}$ \\
\hline 10 & $\begin{array}{l}0.66 \pm 0.20^{c} \\
(0.46-0.86)\end{array}$ & $\begin{array}{l}0.64 \pm 0.20^{\mathrm{b}} \\
(0.44-0.84)\end{array}$ & $\begin{array}{l}0.67 \pm 0.50^{\mathrm{a}} \\
(1.17-0.17)\end{array}$ & $\begin{array}{c}(0.94 \pm 0.04)^{\mathrm{b}} \\
(0.90-0.98)\end{array}$ & $\begin{array}{l}3.74 \pm 0.20^{\mathrm{b}} \\
(3.54-3.94)\end{array}$ & $\begin{array}{l}0.48 \pm 0.04^{\mathrm{b}} \\
(0.44-0.52)\end{array}$ & $\begin{array}{l}4.95 \pm 0.20^{\mathrm{b}} \\
(5.15-4.75)\end{array}$ \\
\hline
\end{tabular}

Note. Values are mean \pm SE, range in parenthesis. Different superscript letters in a column show significant differences $(P<0.05)$ as suggested by General Linear Modelling followed by Tukey's HSD (honest significant difference) at 95\% level of significance.

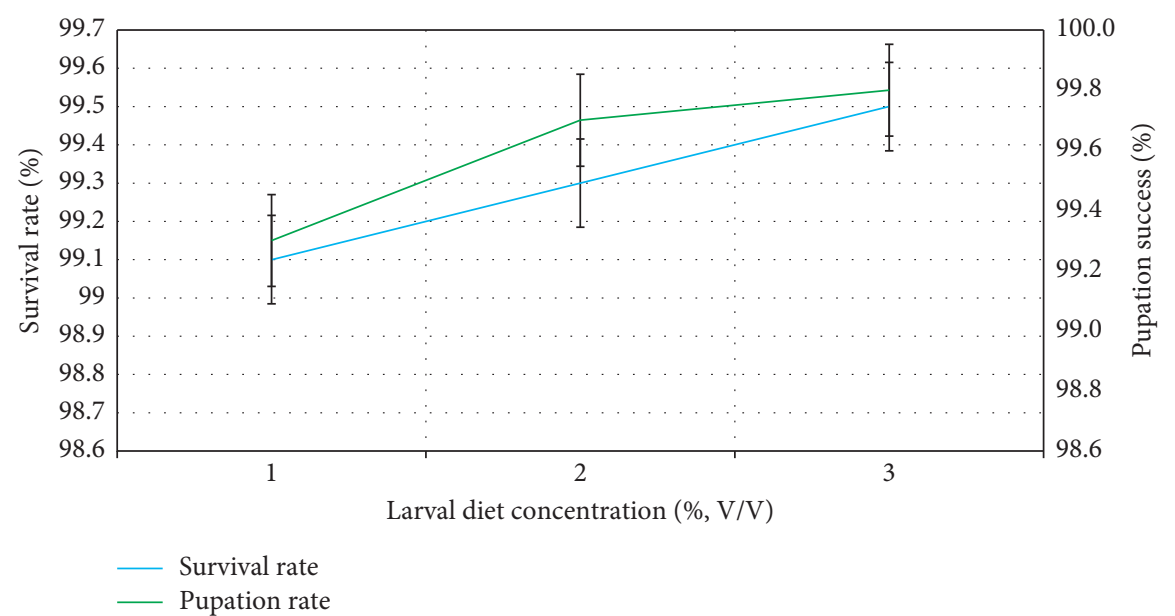

Figure 1: Effect of larval diet concentration (\%, V/V) on survival rate (\%) and pupation success (\%) of larvae of Ae. aegypti.

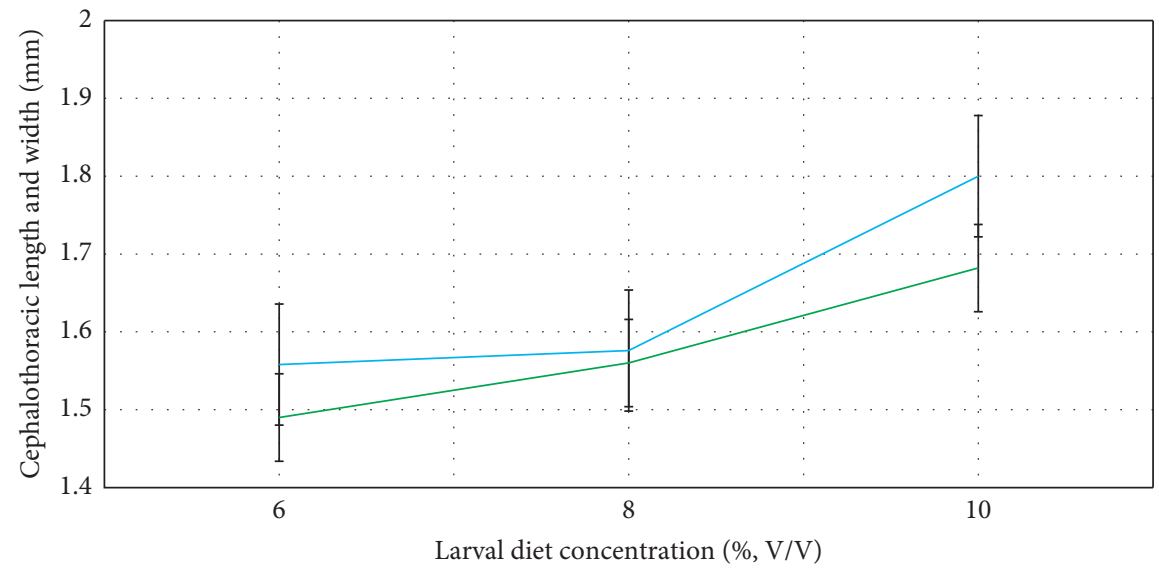

— Cephalothoracic length

Figure 2: Effect of larval diet concentration $(\%, \mathrm{~V} / \mathrm{V})$ on cephalothoracic length $(\mathrm{mm})$ \& cephalothoracic width (mm) of pupae of Ae. aegypti.

females treated under $10 \%$ diet were detected with highest longevity $(37.0 \pm 2.0$ days). Females emerged from larvae treated with low-diet concentrations produced significantly fewer eggs than females provided with high level of food. In addition, the highest biting frequency $(99.60 \pm 0.40 \%)$ and survival rate $(97.95 \pm 0.65 \%)$ of larvae were observed at larvae treated with $10 \%$ diet (Table 4 ).
3.3.3. Vectorial Capacity of Adult Ae. aegypti. Adults reared under the highest dietary treatment $(10 \%)$, were characterized with the highest VC $(196.37 \pm 29.92)$ followed by $8 \%$ larval diet treatment with $(27.30 \pm 4.47)$. Results of GLM indicated that $\mathrm{VC}$ of adult Ae. aegypti differed significantly $\left(F_{4,14}=24.048 ; P=0.014\right.$, at $95 \%$ level of confidence $)$ among the different larval diet concentrations (Figure 4). Similar to 


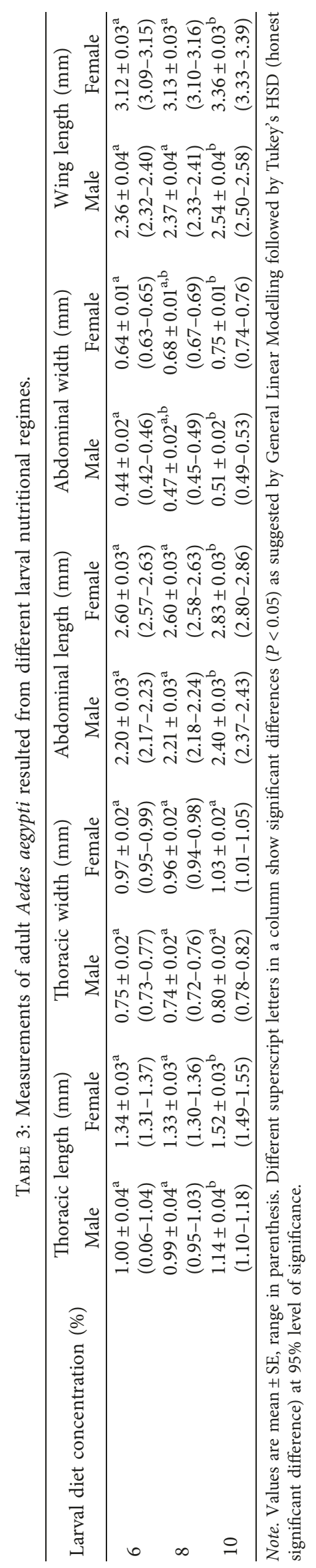


TABLE 4: Biting frequency, longevity, fecundity, and survival rate of adult Aedes aegypti fed with different concentration of larval diet.

\begin{tabular}{lcccc}
\hline Diet concentration (\%) & Biting frequency (\%) & Longevity (days) & Fecundity (number of eggs) & Survival rate (\%) \\
\hline \multirow{2}{*}{6} & $76.56 \pm 1.52^{\mathrm{a}}$ & $33.5 \pm 2.5^{\mathrm{a}}$ & $60.4 \pm 10.8^{\mathrm{a}}$ & $94.95 \pm 0.35^{\mathrm{a}}$ \\
& $(75.04-78.08)$ & $(31.0-36.0)$ & $(49.6-71.2)$ & $(94.60-95.30)$ \\
8 & $82.91 \pm 3.07^{\mathrm{a}}$ & $34.50 \pm 2.5^{\mathrm{a}}$ & $65.24 \pm 6.32^{\mathrm{a}}$ & $95.3 \pm 1.30^{\mathrm{b}}$ \\
& $(82.84-82.98)$ & $(32.0-37.0)$ & $(58.92-71.56)$ & $(94.0-96.6)$ \\
10 & $99.6 \pm 0.4^{\mathrm{b}}$ & $37.0 \pm 2.0^{\mathrm{a}}$ & $116.40 \pm 0.78^{\mathrm{b}}$ & $97.95 \pm 0.65^{\mathrm{b}}$ \\
& $(99.2-100.0)$ & $(35.0-39.0)$ & $(115.62-117.18)$ & $(97.30-98.60)$ \\
\hline
\end{tabular}

Note. Values are mean \pm SE, range in parenthesis. Different superscript letters in a column show significant differences $(P<0.05)$ as suggested by General Linear Modelling followed by Tukey's HSD (honest significant difference) at $95 \%$ level of significance.

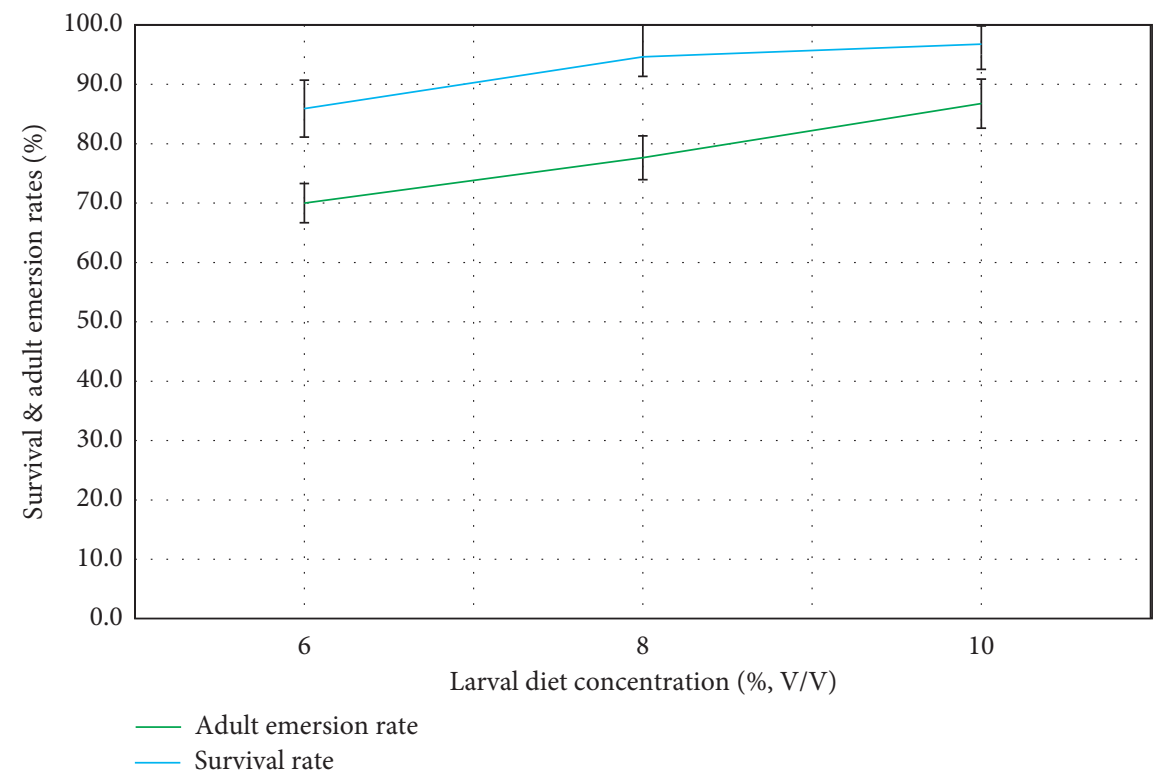

Figure 3: Effect of larval diet concentration (\%, V/V) on survival rate (\%) and adult emersion rate (\%) of pupae of Ae. aegypti.

the previously observed trends, adults produced from the two trays with $8 \%$ and $6 \%$ concentrated diets formed one subset (a), while adults from the highest concentrated diet $(10 \%)$ formed the other subset (b) in terms of VC.

\section{Discussion}

Vectorial capacity (VC) is the capability of a vector to transmit pathogens to a host resulting in a vector-borne disease [18]. It is an important index to predict epidemiological consequences of any entomological change, as vectorial capacity is thus a density-dependent attribute of the mosquito influenced by behavioral, ecological, and environmental factors [25]. Therefore, evaluation of the vectorial capacity of disease vectors is an essential biological parameter to design control strategies in vector control programmes.

The present study investigated the effect of larval diet concentration on life history traits and VC of Ae. aeygpti, which is the main vector for dengue disease transmission. There are several advantages in gathering information related to larval biology, which can be ultimately used in modelling, forecasting population dynamics [26], and improving vector control measures [27]. In addition, it can also be used to improve the existing Ae. aegypti rearing procedures under laboratory in order to promote faster larval development, higher survival rates, and production of homogeneous adult population targeting the release of transgenic or sterile mosquitoes as a vector control measure in the integrated vector management.

According to previous research findings, larval food availability severely influences the growth of larvae and results smaller-sized larvae under low level of larval diet. However, food availability is mostly important in $4^{\text {th }}$ instar larval stage before pupation than first three larval instar stages [28]. Current study revealed that the highest larval growth was examined in the larval diet treatment with 10\% highest concentration. Yet, lowest larval growth was shown by the larvae reared in the $6 \%$ treatment with minimum larval food amount. According to the statistical analysis, most of larval growth parameters varied significantly with different larval dietary concentrations including head length, head width, thoracic width, abdominal length, abdominal width, and total length of larvae.

Only thoracic length did not show a significant difference at different larval diet concentrations. However, life history traits in terms of larval development, female size, and fecundity are affected by larval nutritional stress. Generally, 


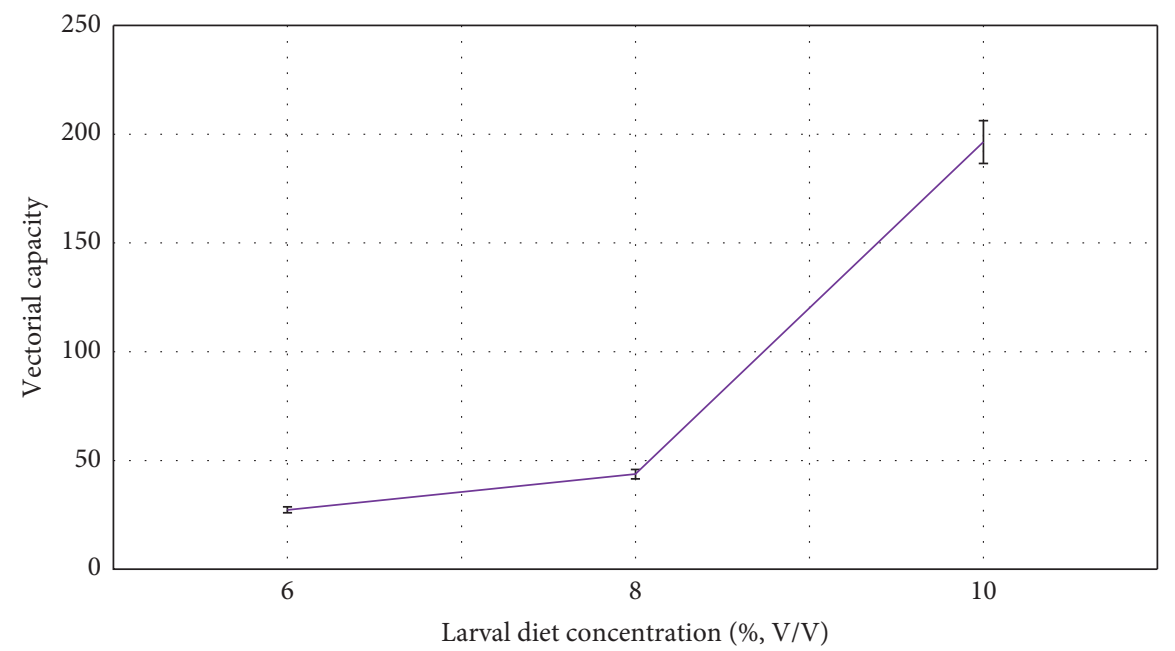

FIgURE 4: Effect of larval diet concentration (\%, V/V) on vectorial capacity of adult Ae. aegypti.

larvae reared under limited food availability conditions need more time to develop and less likely to be gravid than treated with high food [13]. On the other hand, the larval competition for food and other means may enhance dengue viral susceptibility and diminish physiological hindrances to dissemination and transmission, since it could reduce virulence of virus by reducing the force of selection [10].

According to previous studies, sometimes excessive larval diet can reduce larval survival due to the presence of microorganisms, which proliferates unconsumed food availability resulting larval mortality [29]. As investigated by Puggioli et al., the larval development can be either positively or negatively affected depending on the microbial colony, providing additional nutrients to larvae or contaminating feed and make it inedible to larvae [18]. Moreover, according to Lara, poor diet causes an extended larval period, and since immature spend $25 \%$ of their biomass on average moulting, mosquito larvae must acquire enough food supply for ecdysis to avoid a high mortality rate [30].

Some recent studies have indicated that the fitness and health status of adult mosquitoes can be estimated in indirectly by referring to the body size [31]. Significant associations were observed between total length and thoracic length with larval diet levels. In addition to larval growth parameters, cephalothoracic length, and width of pupae varied significantly with larval diet level [31].

In this investigation pupal development was also measured as cephalothoracic length and cephalothoracic width. However, no significant difference was observed between larval diet concentrations with both cephalothoracic length and cephalothoracic width as indicated by the results of GLM. Probably the reason for the above results may be the random and unbiased sampling of pupae for the experimental procedure in the pupal measurements.

The lowest survival rate $(89.1 \pm 0.05 \%)$ was shown by pupae at the lowest larval diet treatment. According to the statistical analysis, the survival of pupae significantly increased with increasing food amounts, probably due to nutrition reserves rich in lipids and that accumulated during the larval stages $[32,33]$. This may account for the high mortality observed from pupae subjected to low food supply. Current study revealed that highest pupation success of larvae was observed at highest larval diet concentration (10\%), and larvae reared under lowest larval diet level (6\%) were characterized with the lowest pupation success. Previous investigations have shown that pupation success (ability of larvae to pupate) is greatly influenced by the nutritional reserves acquired during feeding [34]. According to Chambers and Klowden, mosquito larvae have to achieve a critical weight in order to pupate, allowing the larvae reared with higher food supply probably attain their critical weights earlier than those reared under lower food supply [35].

In addition to the larval and pupal growth, adult body parts are also measured including thoracic length, thoracic width, abdominal length, abdominal width and wing length to study about growth of adult. In accordance with Petersen et al., the measurement of adult body parts also can be used to evaluate the fitness and health of adult mosquitoes indirectly [35].

Findings of the study revealed that the effect of larval diet concentrations on most of measurements of both adult males and females remained significant except for the thoracic width. In fact, the effect of gender on the adult measurements also remained significant. The largest males and females were obtained with highest concentrated diet treatment (10\%) and adults undergo reduction of body size with lowering the concentration of larval diet.

Biting frequency of Ae. aegypti has affected a number of factors such as necessity of intaking small blood meals [36], need to increase fecundity [37], and need to gain additional nutrition to survive in stressful environments [38] and due to host availability. Biting frequency of adult females significantly varied with different larval diet concentrations in accordance with the results of the present study. Adults reared at the highest concentrated diet $(10 \%)$ showed the highest biting frequency $(99.6 \pm 0.40 \%)$, while adults reared at the lowest concentrated diet (6\%) showed the lowest biting frequency $(76.56 \pm 1.52 \%)$.

The group of mosquitoes fed with higher food amounts had relatively higher longevity than adults that emerged 
from larvae reared within a low food environment. However, the longevity of adults was not affected significantly by the food amount available during the larval stages in the present study. As suggested by previous studies, nutrient reserves of adults obtained during the larval stage contribute to an increased the longevity [11], which may explain the shorter longevity of adults derived from the larvae supplied with lower food amount.

Larvae supplied with the higher food amounts resulted adults with higher fecundity and higher survival rate. The amount of food availability to the larvae significantly affected the number of eggs oviposited per female (fecundity) and their survival rate. Current study revealed that the highest VC $(196.37 \pm 29.92)$ was observed at highest larval diet concentration $(10 \%)$, and larvae reared under lowest larval diet level $(6 \%)$ were characterized with the lowest vectorial capacity $(27.30 \pm 4.47)$.

According to previous research findings, smaller females often require two to three blood meals to develop their first batch of eggs and biting frequency may increase the probability of smaller females in acquiring an infectious blood meal [39]. In addition, longer blood meals by larger females may increase the number of parasites ingested, thereby increasing the probability of capturing the infection by the vector $[39,40]$. In malaria vectors, the size of the mosquito also influences oocyst numbers in the midgut of naturally infected mosquitoes, supporting the hypothesis that mosquitoes arising from well-nourished larvae are more competent for parasite transmission [41].

In dengue vectors, some studies have hypothesized that the smaller mosquitoes emerged from high-density treatments with low food availability may enhance susceptibility to dengue virus as smaller mosquitoes may have reduced immune functions [42] and reduced physiological barriers to viral dissemination [43]. However, increase in viral dissemination with time may not directly contribute to enhance VC, since cumulative effect of adult mortality and increase in viral dissemination rate which present at latter incubation period may more unlikely affect VC [10].

The present study did not investigate the vector competence in adult mosquitoes due to limitations in resources and facilities. However, for calculation of vectorial capacity, information on the extrinsic incubation was considered from previously published literature. Current study reported a more than 5-fold increment in the vectorial capacity of $A e$. aegypti, relative to the larvae treated under lowest concentration of diet. Therefore, limitations in larval food availability could have significant biological implications on the vector bionomics of Aedes mosquitoes in the natural environment.

According to the findings of some investigations, it is stated that the larval competition in terms of space or food may result viral strains with shorter extrinsic incubation period in mosquitoes [44]. This phenomenon may also adversely influence on human health since dengue virus isolates with short extrinsic incubation period in mosquitoes are associated with more severe clinical symptoms in humans [45].

\section{Conclusions}

It can be concluded that multiple biological parameters of Ae. aegypti are significantly affected by the amount food provided to larvae. The larvae fed with higher food amounts produced adults with larger wing sizes and longer longevity, greatly increasing the vectorial capacity. Therefore, difference in the quality of larval habitats could have crucial implications for dynamics of dengue transmission. As there are several interplaying factors that affect the viral transmission in the natural environment, these aspects should be further investigated though multifactorial experiments. The present study may also provide essential information for colonization of Ae. aegypti mosquitoes in large scale mass rearing for open release in order to achieve vector reduction by population suppression or replacement strategies.

\section{Data Availability}

The data used to support the findings of this study are available from the corresponding author upon request.

\section{Ethical Approval}

Ethical approval for the current study was obtained from the Ethics Review Committee, Faculty of Medicine, University of Kelaniya (P/155/10/2018).

\section{Conflicts of Interest}

The authors declare that they have no conflicts of interest.

\section{Authors' Contributions}

NG designed and supervised the research and wrote the manuscript. HU conducted laboratory experiments. LU performed statistical analysis and wrote the manuscript. DA supervised the research work and reviewed the manuscript. All authors read and approved the final manuscript.

\section{Acknowledgments}

The authors would like to acknowledge Mr. Tharaka Wijerathne, Temporary Demonstrator, Department of Parasitology, Faculty of Medicine, University of Kelaniya, Sri Lanka, for his assistance. Research activities were supported by the National Research Council (NRC 16-142), Sri Lanka.

\section{References}

[1] G. Benelli, "Research in mosquito control: current challenges for a brighter future," Parasitology Research, vol. 114, no. 8, pp. 2801-2805, 2015.

[2] H. Kampen and D. Werner, "Out of the bush: the Asian bush mosquito Aedes japonicus japonicus (Theobald, 1901) (Diptera, Culicidae) becomes invasive," Parasites \& Vectors, vol. 7, no. 1, p. 59, 2014.

[3] Y.-M. Huang, "The subgenus Stegomyia of Aedes in the Afrotropical Region with keys to the species (Diptera: Culicidae),"Zootaxa, vol. 700, no. 1, pp. 1-20, 2004. 
[4] X. de Lamballerie, E. Leroy, R. N. Charrel, K. Ttsetsarkin, S. Higgs, and E. A. Gould, "Chikungunya virus adapts to tiger mosquito via evolutionary convergence: a sign of things to come?,"Virology Journal, vol. 5, no. 1, p. 33, 2008.

[5] U. Thavara, A. Tawatsin, T. Pengsakul et al., "Outbreak of chikungunya fever in Thailand and virus detection in field population of vector mosquitoes, Aedes aegypti (L.) and Aedes albopictus Skuse (Diptera: Culicidae)," The Southeast Asian journal of tropical medicine, vol. 40, no. 5, p. 951, 2009.

[6] M. Dupont-Rouzeyrol, V. Caro, L. Guillaumot et al., "Chikungunya virus and the mosquito vector Aedes aegypti in New Caledonia (South Pacific Region)," Vector-Borne and Zoonotic Diseases, vol. 12, no. 12, pp. 1036-1041, 2012.

[7] J. L. Kyle and E. Harris, "Global spread and persistence of dengue," Annual Review of Microbiology, vol. 62, no. 1, pp. 71-92, 2008.

[8] "Epidemiology Unit, Ministry of Health: dengue update, Sri Lanka," 2019, http://www.epid.gov.lk/web/index.php? Itemid $=448$.

[9] World Health Organization and Special Programme for Research and Training in Tropical Diseases, Dengue: Guideline for Diagnosis, Treatment, Prevention and Control, World Health Organization, Geneva, Switzerland, 2009.

[10] J. Bara, Z. Rapti, C. E. Cáceres, and E. J. Muturi, "Effect of larval competition on extrinsic incubation period and vectorial capacity of Aedes albopictus for dengue virus," PLoS One, vol. 10, no. 5, Article ID e0126703, 2015.

[11] A. N. Clements, The Biology of Mosquitoes: Development, Nutrition and Reproduction, Vol. 1, Chapman \& Hall, London, UK, 1992.

[12] K. R. P. Singh and A. W. A. Brown, "Nutritional requirements of Aedes aegypti L," Journal of Insect Physiology, vol. 1, no. 3, pp. 199-220, 1957.

[13] A. Vantaux, T. Lefèvre, A. Cohuet, K. R. Dabiré, B. Roche, and O. Roux, "Larval nutritional stress affects vector life history traits and human malaria transmission," Scientific Reports, vol. 6 , no. $1,2016$.

[14] J. R. Wallace and R. W. Merritt, "Influence of microclimate, food, and predation on Anopheles quadrimaculatus (Diptera: Culicidae) growth and development rates, survivorship, and adult size in a Michigan Pond," Environmental Entomology, vol. 28, no. 2, pp. 233-239, 1999.

[15] J. A. Breaux, M. K. Schumacher, and S. A. Juliano, "What does not kill them makes them stronger: larval environment and infectious dose alter mosquito potential to transmit filarial worms," Proceedings of the Royal Society B: Biological Sciences, vol. 281, no. 1786, Article ID 20140459, 2014.

[16] T. Lefevre, A. Vantaux, K. R. Dabire, K. Mouline, and A. Cohuet, "Non-genetic determinants of mosquito competence for malaria parasites," PLoS Pathogens, vol. 9, no. 6, Article ID e1003365, 2013.

[17] L. L. Moller-Jacobs, C. C. Murdock, and M. B. Thomas, "Capacity of mosquitoes to transmit malaria depends on larval environment," Parasites \& Vectors, vol. 7, no. 1, p. 593, 2014.

[18] A. Puggioli, F. Balestrino, D. Damiens et al., "Efficiency of three diets for larval development in mass rearing Aedes albopictus (Diptera: Culicidae)," Journal of Medical Entomology, vol. 50, no. 4, pp. 819-825, 2013.

[19] N. Gunathilaka, T. Ranathunge, L. Udayanga, and W. Abeyewickreme, "Efficacy of blood sources and artificial blood feeding methods in rearing of Aedes aegypti (Diptera: Culicidae) for sterile insect technique and incompatible insect technique approaches in Sri Lanka," BioMed Research International, vol. 2017, Article ID 3196924, 7 pages, 2017.
[20] E. S. Bergo, G. M. Buralli, J. L. F. Santos, and S. M. Gurgel, "Evaluation of the larval development of Anopheles darlingi grown in the laboratory under different diets," Revista de Saúde Pública, vol. 24, no. 2, pp. 95-100, 1990.

[21] M. D.-S. Araujo, L. H. S. Gil, and A. de-Almeida e-Silva, "Larval food quantity affects development time, survival and adult biological traits that influence the vectorial capacity of Anopheles darlingi under laboratory conditions," Malaria Journal, vol. 11, no. 1, p. 261, 2012.

[22] R. E. Gary Jr. and W. A. Foster, "Effects of available sugar on the reproductive fitness and vectorial capacity of the malaria vector Anopheles gambiae (Diptera: Culicidae)," Journal of Medical Entomology, vol. 38, no. 1, pp. 22-28, 2001.

[23] A. P. G. Almeida, S. S. S. G. Baptista, C. A. G. C. C. Sousa et al., "Bioecology and vectorial capacity of Aedes albopictus (Diptera: Culicidae) in Macao, China, in relation to dengue virus transmission," Journal of Medical Entomology, vol. 42, no. 3, pp. 419-428, 2005.

[24] M. Chan and M. A. Johansson, "The incubation periods of dengue viruses," PLoS One, vol. 7, no. 11, Article ID e50972, 2012.

[25] C. Dye, "Intraspecific competition amongst larval Aedes aegypti: food exploitation or chemical interference?," Ecological Entomology, vol. 7, no. 1, pp. 39-46, 1982.

[26] J. M. Depinay, C. M. Mbogo, G. Killeen et al., "A simulation model of African Anopheles ecology and population dynamics for the analysis of malaria transmission," Malaria Journal, vol. 3, no. 1, p. 29, 2004.

[27] H. M. Ferguson, A. Dornhaus, A. Beeche et al., "Ecology: a prerequisite for malaria elimination and eradication," PLoS Medicine, vol. 7, Article ID e1000303, 2010.

[28] S. E. Timmermann and H. Briegel, "Larval growth and biosynthesis of reserves in mosquitoes," Journal of Insect Physiology, vol. 45, no. 5, pp. 461-470, 1999.

[29] J. R. Gilles, R. S. Lees, S. M. Soliban, and M. Q. Benedict, "Density-dependent effects in experimental larval populations of Anopheles arabiensis (Diptera: Culicidae) can be negative, neutral, or overcompensatory depending on density and diet levels," Journal of Medical Entomology, vol. 48, no. 2, pp. 296-304, 2011.

[30] F. M. Lara, Princípios de Entomologia, Ícone Editora, São Paulo, Brazil, 1992.

[31] P. A. D. H. N. Gunathilaka, U. M. H. U. Uduwawala, N. W. B. A. L. Udayanga, R. M. T. B. Ranathunge, L. D. Amarasinghe, and W. Abeyewickreme, "Determination of the efficiency of diets for larval development in mass rearing Aedes aegypti (Diptera: Culicidae)," Bulletin of Entomological Research, vol. 108, no. 5, pp. 583-592, 2018.

[32] J. K. Nayar, "The biology of Culex nigripalpus Theobald (Diptera: Culicidae) Part 2. Adult characteristics at emergence and adult survival without nourishment," Journal of Medical Entomology, vol. 5, no. 2, pp. 203-210, 1968.

[33] R. W. Merritt, R. H. Dadd, and E. D. Walker, "Feeding behavior, natural food, and nutritional relationships of larval mosquitoes," Annual Review of Entomology, vol. 37, no. 1, pp. 349-374, 1992.

[34] G. M. Chambers and M. J. Klowden, "Correlation of nutritional reserves with a critical weight for pupation in larval Aedes aegypti mosquitoes," Journal of the American Mosquito Control Association, vol. 6, no. 3, pp. 394-399, 1990.

[35] V. Petersen, M. J. Marchi, D. Natal, M. T. Marrelli, A. C. Barbosa, and L. Suesdek, "Assessment of the correlation between wing size and body weight in captive Culex quinquefasciatus," Revista da Sociedade Brasileira de Medicina Tropical, vol. 49, no. 4, pp. 508-511, 2016. 
[36] M. J. Klowden, "Effects of sugar deprivation on the hostseeking behaviour of gravid Aedes aegypti mosquitoes," Journal of Insect Physiology, vol. 32, no. 5, pp. 479-483, 1986.

[37] H. Briegel and E. Hörler, "Multiple blood meals as a reproductive strategy in Anopheles (Diptera: Culicidae)," Journal of Medical Entomology, vol. 30, no. 6, pp. 975-985, 1993.

[38] W. Knülle, "Significance of fluctuating humidities and frequency of blood meals on the survival of the spiny rat mite, Echinolaelaps echidninus (Berlese)," Journal of Medical Entomology, vol. 4, no. 3, pp. 322-325, 1967.

[39] J. R. Schneider, A. C. Morrison, H. Astete, T. W. Scott, and M. L. Wilson, "Adult size and distribution of Aedes aegypti (Diptera: Culicidae) associated with larval habitats in Iquitos, Peru," Journal of Medical Entomology, vol. 41, no. 4, pp. 634-642, 2004

[40] B. A. Okech, L. C. Gouagna, G. Yan, J. I. Githure, and J. C. Beier, "Larval habitats of Anopheles gambiae s.s. (Diptera: Culicidae) influences vector competence to Plasmodium falciparum parasites," Malaria Journal, vol. 6, no. 1, p. 50, 2007.

[41] E. O. Lyimo and J. C. Koella, "Relationship between body size of adult Anopheles gambiae s.l. and infection with the malaria parasite Plasmodium falciparum," Parasitology, vol. 104, no. 2, pp. 233-237, 1992.

[42] A. Telang, A. A. Qayum, A. Parker, B. R. Sacchetta, and G. R. Byrnes, "Larval nutritional stress affects vector immune traits in adult yellow fever mosquito Aedes aegypti (Stegomyia aegypti)," Medical and Veterinary Entomology, vol. 26, no. 3, pp. 271-281, 2012.

[43] P. R. Grimstad and E. D. Walker, "Aedes triseriatus (Diptera: Culicidae) and La Crosse virus. IV. Nutritional deprivation of larvae affects the adult barriers to infection and transmission," Journal of Medical Entomology, vol. 28, no. 3, pp. 378-386, 1991.

[44] T. Nidelet, J. C. Koella, and O. Kaltz, "Effects of shortened host life span on the evolution of parasite life history and virulence in a microbial host-parasite system," BMC Evolutionary Biology, vol. 9, no. 1, p. 65, 2009.

[45] J. R. Anderson and R. Rico-Hesse, “Aedes aegypti vectorial capacity is determined by the infecting genotype of dengue virus," The American Journal of Tropical Medicine and Hygiene, vol. 75, no. 5, pp. 886-892, 2006. 


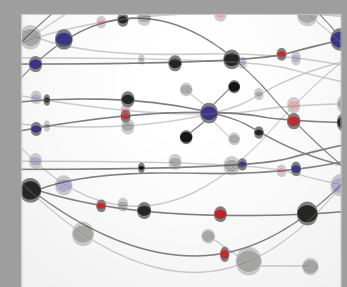

The Scientific World Journal
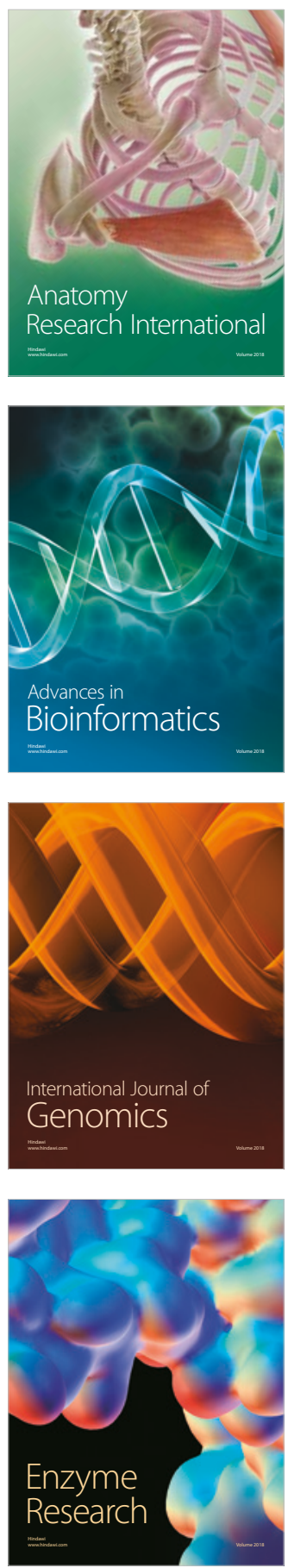
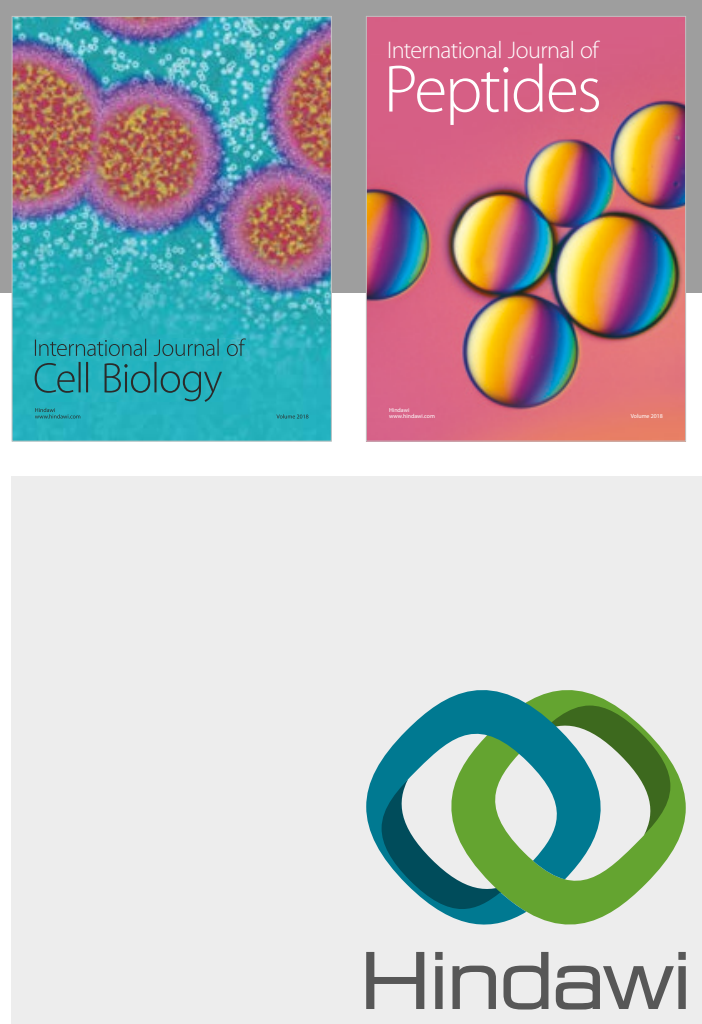

Submit your manuscripts at

www.hindawi.com
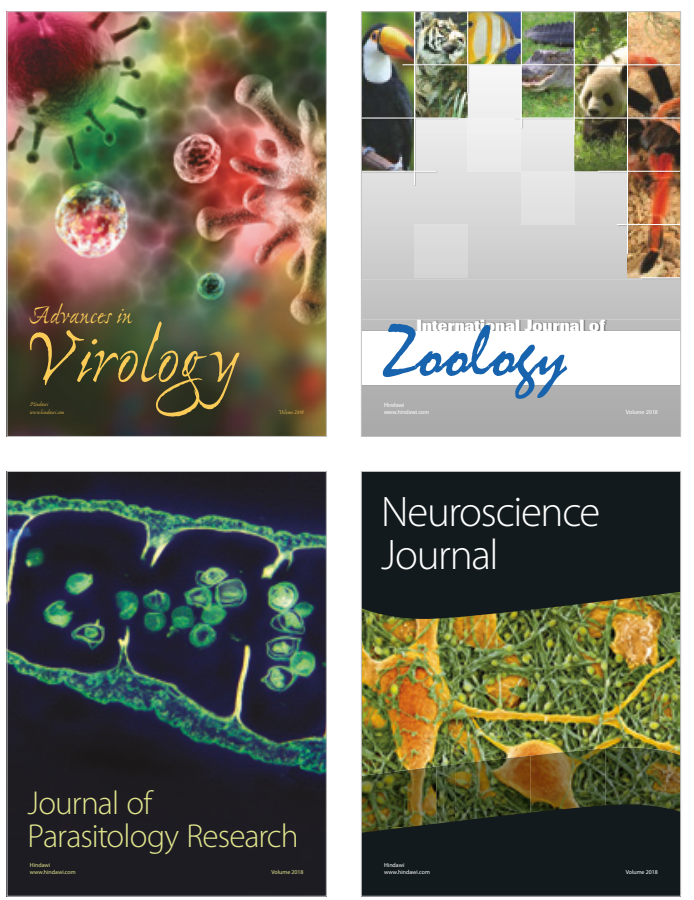
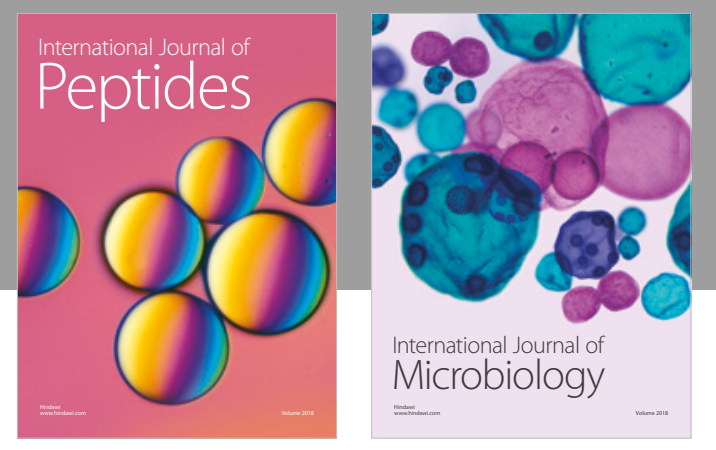

nternational Journal of Microbiology
Journal of
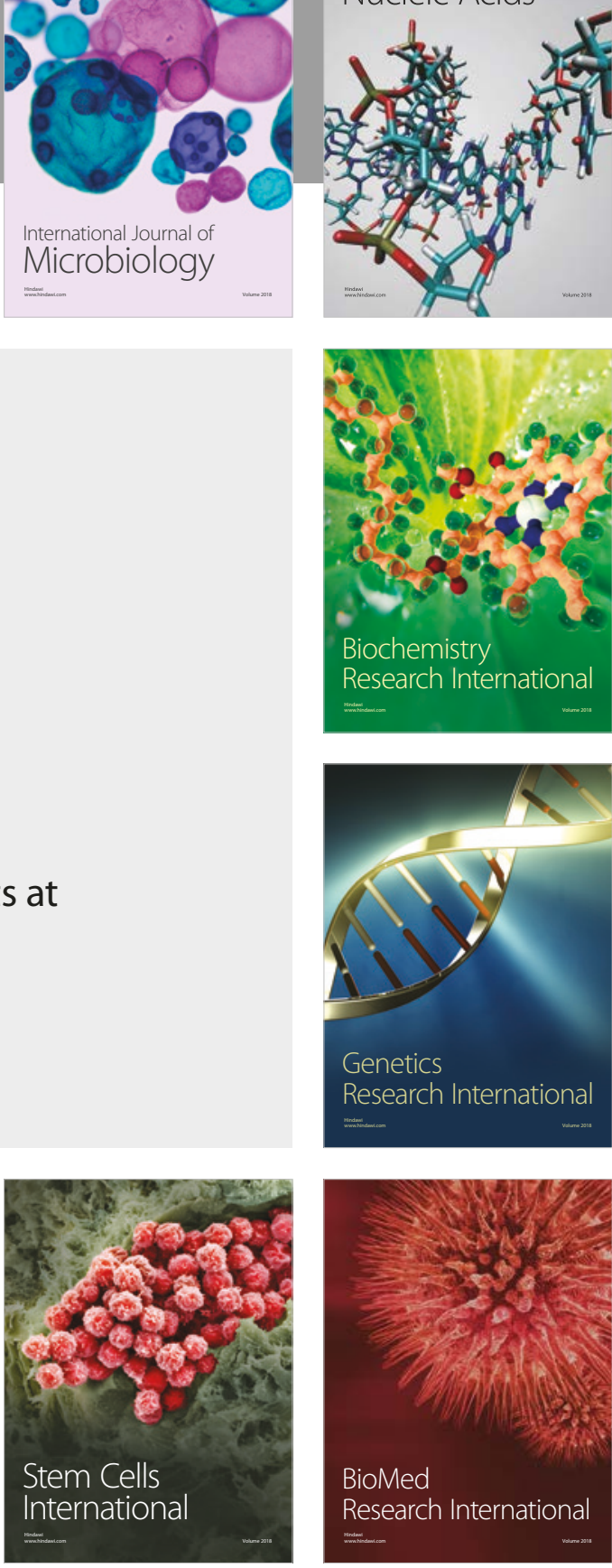
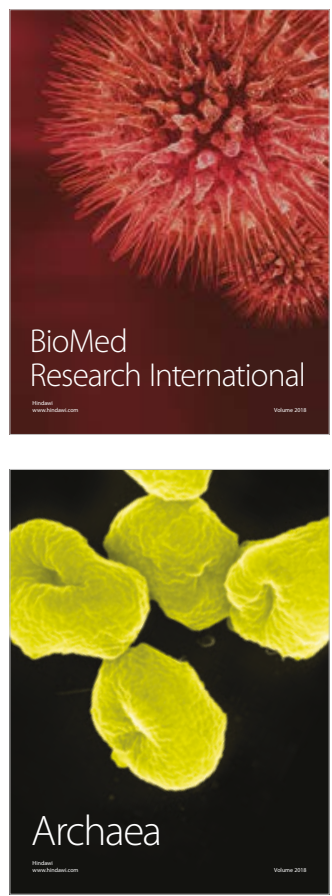